\title{
Prostorski prikaz razvoja osmerozobega smrekovega lubadarja (Ips typographus) na območju Slovenije
}

\section{Nikica OGRIS*}

\section{Uvod}

Osmerozobi smrekov lubadar (Ips typographus Linnaeus, 1758) velja za eno ekonomsko najpomembnejših vrst podlubnikov na navadni smreki (Picea abies (L.) H. Karst.) v Srednji Evropi (Wermelinger in Seifert, 1998.; Wermelinger, 2004). V skladu s Pravilnikom o varstvu gozdov (2009) v Sloveniji poteka redno spremljanje gostote populacije smrekovih podlubnikov. Za namen ugotavljanja prekomerne namnožitve smrekovih lubadarjev se uporabljajo kontrolne pasti s specifičnimi feromonskimi pripravki ter kontrolne nastave. Obstoječi sistem kontrolnih feromonskih pasti za spremljanje gostote populacije smrekovih lubadarjev je enoten za celotno območje Slovenije in ne upošteva lokalnih razlik v geografskih, klimatskih in ekoloških značilnostih posameznih območij, ki pomembno vplivajo na populacijsko dinamiko smrekovih lubadarjev.

V srednji Evropi se za spremljanje razvoja osmerozobega smrekovega lubadarja pogosto uporablja fenološki model PHENIPS (Baier in sod., 2007; Berec in sod., 2013). Model PHENIPS omogoča natančno določitev datuma prvega rojenja in datum konca prve generacije hroščev v odvisnosti od lokalnih klimatskih in geografskih razmer. Ogris (2017a) je implementiral in prilagodil fenološki model PHENIPS (Baier in sod., 2007) za simulacijo sezonskega razvoja osmerozobega smrekovega lubadarja v prostoru in času na območju Slovenije. Model je poimenoval RITY-1, kar je kratica za Razvoj Ips TYpographus, različica 1. Model RITY-1 omogoča izračun potencialnega razvoja osmerozobega smrekovega lubadarja za poljubno točko v Sloveniji. Model je implementiral v spletni interaktivni aplikaciji, kjer uporabnik določi želen kraj, leto obravnave in izbere ali želi uporabiti interpolacijo temperature zraka na točno določeno lokacijo glede na njeno nadmorsko višino (Ogris, 2017b).

Trenutna implementacija modela RITY-1 omogoča izračun potencialnega razvoja $I$. typographus za konkretno lokacijo (v nadaljevanju RITY-1-XY), ne omogoča pa prostorskega prikaza za celo območje Slovenije naenkrat. Cilj naše raziskave je bil nadgraditi model RITY-1-XY, tako da bo omogočal prostorski prikaz potencialnega razvoja osmerozobega smrekovega lubadarja (v nadaljevanju RITY-1-GIS).

\section{Metode dela}

Prostorski model RITY-1-GIS je v osnovi enak modelu RITY-1-XY s to razliko, da uporablja metode za prostorsko obdelavo podatkov. Vhodni podatki v model so minimalna, povprečna in maksimalna dnevna temperatura zraka iz sistema INCA (ARSO, 2017), ki ima prostorsko ločljivost $1 \mathrm{~km} \times 1 \mathrm{~km}$, meteorološke spremen- ljivke napove za 12 ur naprej s korakom ene ure. Vgradili smo tudi možnost napovedi razvoja I. typographus za sedem dni vnaprej in za ta namen smo uporabili podatke o temperaturi zraka izključno iz sistema INCA ne pa tudi iz numeričnega meteorološkega modela ALADIN-SI (Pristov in sod., 2012), ki jih uporabljamo pri izračunu napovedi zraka v točkovnem modelu RITY-1XY.

Prostorska ločljivost modela RITY-1-GIS je $1 \mathrm{~km} \times$ $1 \mathrm{~km}$, kar je pogojeno s podatki o temperaturi zraka iz sistema INCA. Časovna ločljivost modela je en dan. Model se samodejno izračuna vsak dan med 1. aprilom in 31. oktobrom. Z modelom RITY-1-GIS lahko na karti prikažemo potencialni dan, ko nastopi rojenje, napad drevesa, začetek in konec razvoja posameznih čistih in sestrskih generacij in spremljamo lahko razvoj osmerozobega smrekovega lubadarja po razvojnih fazah od jajčeca, ličinke, bube, mladega hrošča do odrasle žuželke.

Postopek izračuna RITY-1-GIS sledi postopku izračuna RITY-1-XY (Ogris, 2017a). V nadaljevanju podajamo povzetek tega postopka $\mathrm{z}$ navedbo razlik med obema postopkoma.

1. Pridobitev podatkov o dnevni temperaturi zraka iz sistema INCA.

2. Izračun manjkajočih podatkov o temperaturi zraka $\mathrm{s}$ pomočjo prostorske linearne regresije za zadnjih sedem dni pred manjkajočim podatkom (glej poglavje o tehničnih podatkih o modelu RITY-1-GIS).

3. Napoved temperature zraka za naslednjih sedem dni. $\mathrm{Za}$ ta namen uporabimo samo podatke modela INCA, ne pa tudi podatke modela ALADIN-SI, ki jih uporabljamo pri napovedi temperature zraka $\mathrm{v}$ modelu RITY-1-XY. Napoved izračunamo s prostorsko linearno regresijo.

4. Izračun dolžine dneva.

5. Izračun kumulativne vsote efektivnih temperatur zraka nad pragom $8,3^{\circ} \mathrm{C}$.

6. Izračun datuma pričetka rojenja.

7. Izračun datuma prvega napada.

8. Izračun kumulativne efektivne temperature skorje.

9. Izračun razvoja prve čiste generacije.

10. Izračun nastopa in razvoja ostalih čistih generacij.

11. Izračun nastopa in razvoja sestrskih generacij.

12. Izračun števila čistih in sestrskih generacij.

13. Priprave karte za prikaz v spletni aplikaciji, ki jo shranimo v formatu PNG v podatkovni zbirki spletnega portala za varstvo gozdov (Ogris, 2011).

Vsi zgoraj navedeni izračuni upoštevajo razširjenost navadne smreke, tj. model se izračuna samo za modelske celice, kjer je prisotna navadna smreka. Razširjenost navadne smreke smo pridobili iz podatkovne zbirke 
Gozdni fondi (2015), ki jo ureja Zavod za gozdove Slovenije. Podatki v zbirki Gozdni fondi se nanašajo na nivo gozdnega sestoja. Podatke smo grafično pretvorili, tako da so se ujemali z mrežo modela RITY-1-GIS. Kjer je bila lesna zaloga navadne smreke $\mathrm{v}$ modelski celici večja kot nič, smo vrednost celice označili z ena v nasprotnem primeru pa z nič (slika 1). Slednjo karto smo uporabili za omejitev izračuna modela RITY-1-GIS.

Pripravili smo dve spletni aplikaciji:

- prva ponuja pregled celega območja Slovenije povezava: http://www.zdravgozd.si/prognoze zapis.aspx?idpor $=35$

- druga je $\mathrm{v}$ obliki interaktivne spletne karte povezava: http://www.zdravgozd.si/projekti/podlubniki/karta.aspx

\section{Pregled celega območja Slovenije}

V tej spletni aplikaciji imamo na voljo tri parametre, s katerimi nastavimo prikaz karte: leto, vrsta karte in datum (slika 2). Prva dva parametra sta v obliki spustnega seznama, tretji pa je v obliki drsnega traku. Z letom določimo sezono, za katero želimo pregledovati karte razvoja osmerozobega smrekovega lubadarja. Lahko izbiramo med naslednjimi vrstami kart: razvoj 1.-4. čiste in sestrske generacije, število čistih in sestrskih generacij, pričetek razvoja 1. in 2. čiste generacije. V tej aplikaciji imamo na voljo samo omejen nabor vrst kart, na interaktivni karti imamo na voljo razširjen nabor grafičnih slojev. Pri izbiri vrste karte so v oklepaju navedene tri možnosti: MAX - najhitrejša možnost razvoja, MIN najpočasnejša možnost razvoja in AVG - srednja možnost razvoja I. typographus. Z drsnim trakom nastavimo datum v izbranem letu, za katerega želimo prikazati karto (s klikom na levi miškin gumb in vlek v levo ali desno stran, lahko pa si pomagamo s smernimi tipkami na tipkovnici). Pod drsnim trakom so na voljo kontrolni gumbi, s katerimi se lahko premikamo za en dan naprej ali nazaj, na začetek (1. april), ali na konec (31. oktober) ter gumba za zagon in zaustavitev samodejne animacije.

$\mathrm{Na}$ karti razvoja generacije razvojno fazo I. typographus označuje barva: bela - razvoj se še ni pričel, modra - jajčece, zelena - ličinka, svetlozelena - buba, oranžna - mladi hrošč, rdeča - odrasel hrošč, vijolična mirovanje ali pogin. Razvojna faza je določena glede na relativni delež potrebne vsote efektivnih temperatur skorje za popolni razvoj ene generacije, kar znaša $557{ }^{\circ} \mathrm{C}$ : jajčece $(10 \%)$, ličinka $(50 \%)$, buba $(60 \%)$, mladi hrošč $(100 \%)$, odrasel hrošč pogine ali prične $\mathrm{z}$ mirovanjem (150\%). Število generacij je na karti označeno z barvo: bela (nič), zelena (ena), svetlo zelena (dve), oranžna (tri), rdeča (štiri). Pričetek razvoja generacije je označen s temno rjavo barvo, če se izbrana generacija še ni pričela razvijati je to na karti označeno $\mathrm{z}$ belo barvo.

\section{Interaktivna karta}

$\mathrm{Na}$ interaktivni spletni karti imamo na voljo več orodij in možnosti za analizo kot pri prej opisani osnovni spletni aplikaciji. Za osnovno grafično podlago za orientacijo $\mathrm{v}$ prostoru lahko izbiramo med tremi sloji (slika 3): topografska karta (GURS), digitalni ortofoto (GURS) in meje gozdnogospodarskih območij Zavoda za gozdove Slovenije (GGO). Model RITY-1-GIS ima naslednje možne grafične sloje: razvoj 1.-5. čiste generacije, razvoj 1.-4. sestrske generacije, število čistih in sestrskih generacij, prvo spomladansko rojenje, pričetek razvoja 1.-5. čiste generacije, pričetek razvoja 1.-4. sestrske generacije. Vsi grafični sloji v interaktivni karti se nanašajo na srednjo možnost razvoja (AVG), razen pričetek rojenja in pričetek razvoja 1. čiste generacije, ki se nanašta na najhitrejšo možnost razvoja. Vse navedene grafične sloje lahko poljubno vklapljamo ali izklapljamo.

$\mathrm{Na}$ vrhu spletnega obrazca interaktivne karte imamo na voljo naslednje kontrolnike (slika 3): (1) spustni seznam, v katerem izberemo leto analize; (2) drsni trak, s katerim izberemo dan med 1. aprilom in 31. oktobrom $\mathrm{v}$ izbranem letu; (4) v napisu Datum se izpiše izbrani dan; (5) gumb Poizvedba; (6) povezavi do opisa modela RITY-1-GIS in RITY-1-XY; (7) set standardnih kontrolnikov za delo s karto, kot so približaj, oddalji, premakni, tiskanje, iskanje, merjenje razdalj in površin ter pregledna karta. Legenda barv je $\mathrm{v}$ interaktivni karti enaka kot v osnovni spletni aplikaciji za hiter pregled nad območjem cele Slovenije in je prikazana $\mathrm{v}$ obrazcu s seznamom grafičnih slojev.

S pritiskom na gumb Poizvedba naredimo poizvedbo za poljubno točko v Sloveniji za izbrani dan. Ko na karti izberemo lokacijo, se odpre obrazec $\mathrm{z}$ rezultati poizvedbe, kjer so navedene vrednosti vseh atributov modela RITY-1-GIS (slika 4). V oklepaju so navedene tri možnosti: MAX - najhitrejša možnost razvoja, MIN - najpočasnejša možnost razvoja in AVG - srednja možnost razvoja I. typographus. Razvoj čistih in sestrskih generacij je izražen v deležu potrebne vsote efektivnih temperatur skorje za popolni razvoj ene generacije $(\mathrm{K}=557$ ${ }^{\circ} \mathrm{C}$ ), npr. vrednost 1,0 pomeni, da se je generacija v polnosti razvila in odrasli hrošči so izleteli iz napadenega drevesa, vrednost 0,56 pomeni, da je generacija v razvojni fazi bube (glej opis osnovne spletne aplikacije). Poleg rezultatov imamo na voljo povezavo do spletne aplikacije, ki nam za izbrano lokacijo izriše grafikon poteka razvoja čistih in sestrskih generacij (model RITY1-XY:

http://www.zdravgozd.si/prognoze zapis.aspx?idpor=32).

\section{Tehnični podatki o modelu RITY-1-GIS}

Prostorska podatkovna zbirka je $\mathrm{v}$ formatu Microsoft SQL Server 2016, podatki so shranjeni v ESRI raster katalogu v podatkovnem tipu ESRI ST_Raster. Algoritem za izračun modela RITY-1-GIS je napisan s pomočjo programskega orodja Microsoft Visual Studio 2015 in programskega okvirja Microsoft .NET Framework 4.6. Za delo z rastri, npr. njihovo seštevanje in množenje, smo uporabili knjižnico GDAL (2014). Prostorsko interpolacijo manjkajočih podatkov o temperaturi zraka in prostorsko interpolacijo napovedi temperature zraka smo izvedli s pomočjo statističnega programa R (R Core Team, 2016). Pri tem smo uporabili knjižnici za delo z rastri, tj. knjižnico raster (Hijmans, 2016) in knjižnico rgdal (Bivand in sod., 2016). Za vzporedno procesiranje prostorske interpolacije smo uporabili knjižnico snow (Tierney in sod., 2016). Posamezno karto za prikaz v spletni aplikaciji smo izdelali s pomočjo spletne storitve 
MapPrint na strežniški programski opremi ESRI ArcGIS Server 10.4.1. Interaktivna spletna karta teče na Microsoft Internet Information Services 8.0 in je bila razvita $\mathrm{S}$ pomočjo programskega vmesnika ESRI ArcGIS API for JavaScript 3.16.

\section{Primer kart razvoja I. typographus v Sloveniji v letu 2016}

$\mathrm{Na}$ dan 15. 6. 2016 se je prva čista generacija nahajala v razvojni fazi mladega hrošča na okoli polovici modelskih celic $(50,3 \%)$, le slaba petina modelskih celic $(19,3 \%)$ je potencialno izpolnila temperaturne pogoje za razvoj do odraslega hrošča (preglednica 1). Ostale razvojne faze 1 . čiste generacije so se na ta dan nahajale na slabi tretjini $(30,4 \%)$ modelske površine. Razvoj 1. čiste generacije se po srednji možnosti (AVG) in do izbranega dne še ni pričel na 2,8 \% modelskih celic in je obsegal najvišje predele Alp in Snežnika (slika 5). Razvojna faza odraslega hrošča je bila potencialno prisotna na vzhodu, Ljubljanski kotlini in zahodu Slovenije vse do Tolmina.

Prva sestrska generacija se je na dan 15. 6. 2016 potencialno nahajala $v$ razvojni fazi ličinke na polovici modelskih celic $(52,2 \%)$, na $14,4 \%$ modelske površine v fazi bube, na $2,1 \%$ površine $v$ razvojni fazi mladega hrošča (preglednica 1). Odrasel hrošč prve sestrske generacije na ta dan po srednji možnosti razvoja še ni bil prisoten nikjer v Sloveniji. Razvoj prve sestrske generacije se verjeno ni pričel na $23,1 \%$ modelske površine (slika 6), kar je zajemalo predele $\mathrm{z}$ višjo nadmorsko višino, tj. Alpe, Pohorje, Dinarsko gorstvo in ostale višje predele drugod po Sloveniji.

Model RITY-1 se izračunava od 1. aprila do 31. oktobra. Pri izračunu števila generacij upošteva vse generacije, ki so se razvile do odrasle žuželke (imaga) in zadnjo generacijo, ki se je razvila do mlade žuželke, ki lahko uspešno preživi zimo (Baier in sod., 2007). Pri izračunu števila generacij smo upoštevali srednjo možnost (AVG). Do konca sezone 2016 so se po modelu RITY1-GIS na pretežnem delu Slovenije razvile tri čiste generacije $(65,1 \%$ modelske površine) in dve sestrski generaciji (na 54,9\% modelskih celic) (preglednica 2). Na manjšem območju so bili potencialno izpolnjeni pogoji za razvoj štirih čistih generacij, tj. na območju v okolici Nove Gorice (slika 7). Za razvoj osmerozobega smrekovega lubadarja niso bili ustrezni temperaturni pogoji samo na najvišjih predelih Alp (1,4 \% površine). Potencialno so se lahko v 2016 na tretjini modelskih celic $(29,6$ \%) razvile tri sestrske generacije, tj. v nižjih predelih vzhodne, osrednje in zahodne Slovenije (slika 8). Neustrezni pogoji za razvoj sestrske generacije so obsegali 3,5 \% površine modela, tj. najvišje predele Alp.

\section{Validacija modela na primeru rojenja}

Model RITY-1-GIS smo preverili na primeru prvega spomladanskega rojenja osmerozobega smrekovega lubadarja. Najprej smo analizirali ulov osebkov I. typographus v 2.627 kontrolnih pasteh v letu 2016, ki ga je izvajal in beležil Zavod za gozdove Slovenije (ZGS, 2016). Pričetek rojenja smo definirali kot prvi dan, ko je bilo v kontrolni pasti ujetih več kot 100 osebkov od zadnjega ulova (čiščenje pasti se je v povprečju izvajalo na 18 dni). Prvo rojenje je bilo zabeleženo 29. 3. 2016, ko je bil zabeležen ulov v 13. kontrolnih pasteh z več kot 100 osebkov (slika 9). Potem je število pasti, ki so zaznale rojenje, strmo naraščalo do 18. 4. 2016, nakar se je umirilo do 2. 5. 2016. Zato smo za validacijo modela na primeru rojenja vzeli datum 18. 4. 2016. Do tega dne je bil pričetek rojenja zabeležen v 701 kontrolnih pasteh. Model RITY-1-GIS je pravilno predvidel rojenje v 94,2 $\%$ kontrolnih pasteh (slika 10). Zato lahko domnevamo, da model RITY-1 napove rojenje I. typographus z zadovoljivo točnostjo in natančnostjo.

Model, ki ga opisujemo v tem prispevku, še ni v celoti preverjen in kalibriran za območje Slovenije. To bomo storili v okviru projekta Razvoj metod zaznavanja poškodb iglavcev zaradi smrekovih in jelovih podlubnikov ter izdelava modelov za napovedovanje namnožitev smrekovih in jelovih podlubnikov v slovenskih razmerah, ki se je začel v 2016 in traja do 2019. Model je še v razvojni fazi in ga bomo tekom projekta še preverili in izboljšali.

\section{Zahvala}

Raziskava je nastala v okviru projekta Razvoj metod zaznavanja poškodb iglavcev zaradi smrekovih in jelovih podlubnikov ter izdelava modelov za napovedovanje namnožitev smrekovih in jelovih podlubnikov v slovenskih razmerah (V4-1623), ki ga financirata Ministrstvo za kmetijstvo, gozdarstvo in prehrano ter Javna agencija za raziskovalno dejavnost Republike Slovenije iz državnega proračuna. Zahvaljujemo se Zavodu za gozdove Slovenije za podatke o ulovu podlubnikov v kontrolnih pasteh za leto 2016 .

\section{Viri}

ARSO. 2017. Podatki sistema INCA. Ljubljana, Agencija Republike Slovenije za okolje.

Baier P., Pennerstorfer J., Schopf A. 2007. PHENIPS - A comprehensive phenology model of Ips typographus (L.) (Col., Scolytinae) as a tool for hazard rating of bark beetle infestation. Forest Ecology and Management, 249: 171-186.

Berec L., Doležal P., Hais M. 2013. Population dynamics of Ips typographus in the Bohemian Forest (Czech Republic): Validation of the phenology model PHENIPS and impacts of climate change. Forest Ecology and Management, 292: 1-9.

Bivand R., Keitt T., Rowlingson B. 2016. rgdal: Bindings for the Geospatial Data Abstraction Library. $\mathrm{R}$ package version 1.2-5. https://CRAN.R-project.org/package=rgdal

GDAL. 2014. GDAL - Geospatial Data Abstraction Library: Version 1.1.1, Open Source Geospatial Foundation, http://www.gdal.org/

Hijmans R.J. 2016. raster: Geographic Data Analysis and Modeling. $\mathrm{R}$ package version 2.5-8. https://CRAN.R-project.org/package $=$ raster

Ogris N. 2011. E-varstvo gozdov Slovenije: Portal. V: 10. slovensko posvetovanje o varstvu rastlin z mednarodno udeležbo, 2011 March 1-2. Maček J., Trdan S. (ur.). Podčetrtek, Društvo za varstvo rastlin Slovenije: 237-240. URL: www.zdravgozd.si

Ogris N. 2017a. Fenološki model za osmerozobega smrekovega lubadarja (Ips typographus) RITY-1 na območju Slovenije. Napovedi o zdravju gozdov, 2017. URL: http://www.zdravgozd.si/prognoze_zapis.aspx?idpor=33. DOI: $10.20315 / \mathrm{NZG} .33$

Ogris N. 2017b. Spletna aplikacija za izračun fenološkega modela za osmerozobega smrekovega lubadarja (Ips typographus) RITY-1. Napovedi o zdravju gozdov, 2017. URL: http://www.zdravgozd.si/prognoze zapis.aspx?idpor=32. DOI: $10.20315 / \mathrm{NZG} .32$

Pravilnik o varstvu gozdov (Uradni list RS, št. 114/09 in 31/16)

Pristov N., Cedilnik J., Jerman J., Strajnar B. 2012. Priprava numerične meteorološke napovedi ALADIN-SI. Veternica, 4: 17-22.

R Core Team. 2016. R: A language and environment for statistical computing. R Foundation for Statistical Computing, Vienna, Austria. URL https://www.R-project.org. 
Tierney L., Rossini A. J., Li N., Sevcikova H. 2016. snow: Simple Network of Workstations. R package version 0.4-2. https://CRAN.Rproject.org/package $=$ snow

Wermelinger B. 2004. Ecology and management of the spruce bark beetle Ips typographus: a review of recent research. Forest Ecology and Management, 202, 1-3: 67-82.

Wermelinger B., Seifert M. 1998. Analysis of temperature dependent development of the spruce bark beetle Ips typographus (L.) (Col. Scol.). Journal of Applied Entomology, 122: 185-191.

ZGS. 2015. Gozdni fondi. Podatkovna zbirka, Zavod za gozdove Slovenije.

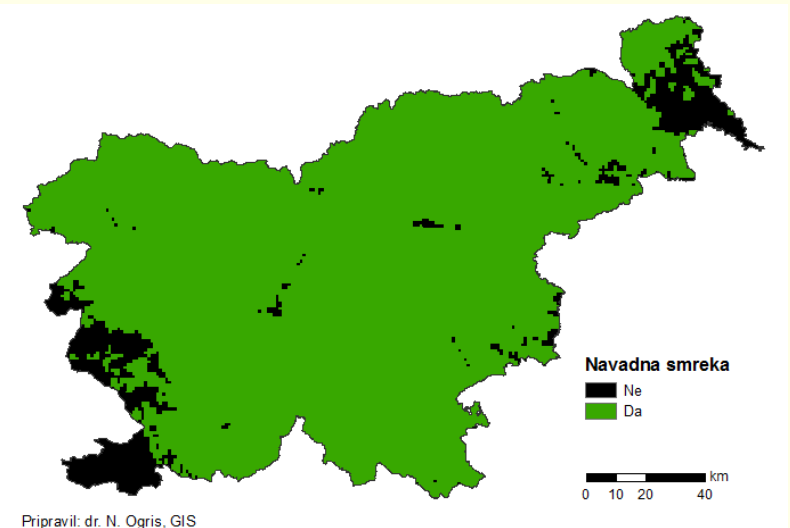

Pripravil: dr. N. Ogris, GIS
Podlage: razširjenost navadne smreke (ZGS), meja Slovenije (GURS)

Slika 1: Model RITY-1-GIS upošteva razširjenost navadne smreke v Sloveniji

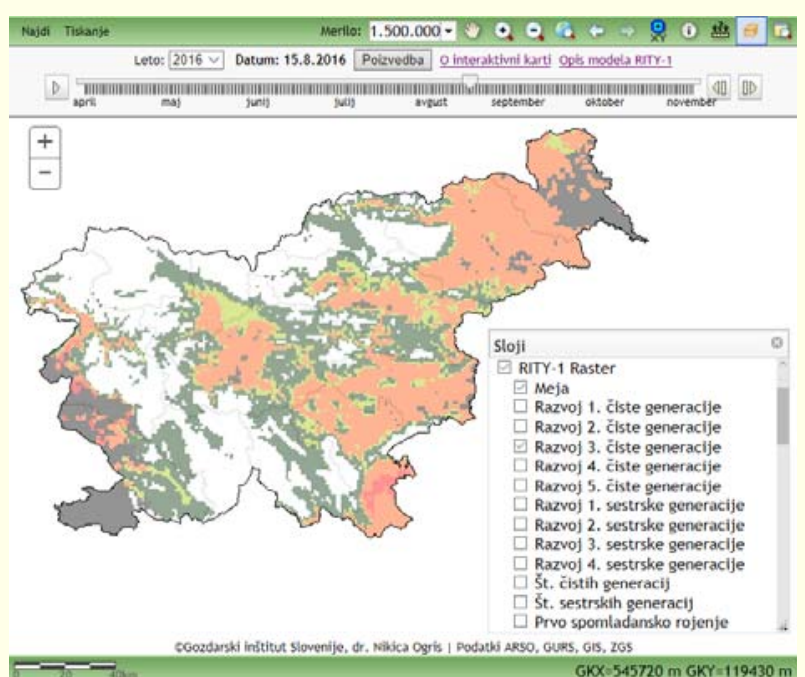

Slika 3: Interaktivna spletna karta za prostorski pregled razvoja osmerozobega smrekovega lubadarja, model RITY-1 (http://www.zdravgozd.si/projekti/podlubniki/karta.aspx)
ZGS. 2016. Podatki o ulovu v kontrolno-lovne pasti. V: Računalniški program Varstvo gozdov, N. Ogris (ur.). Ljubljana, Gozdarski inštitut Slovenije in Zavod za gozdove Slovenije.

${ }^{1}$ Gozdarski inštitut Slovenije, Večna pot 2, 1000 Ljubljana "nikica.ogris@gozdis.si


Interaktivna karta

Analiza razvoja osmerozobega smrekovega lubadarja na interaktivni karti.

Slika 2: Spletna aplikacija za prostorski prikaz razvoja osmerozobega smrekovega lubadarja (Ips typographus), model RITY-1 (http://www.zdravgozd.si/prognoze zapis.aspx?idpor=35)

\section{Rezultati poizvedbe}

$X: 460987, Y: 103158$

Datum: 15. 08. 2016

\section{Grafikon poteka razvoja}

Razvoj 1. čiste generacije (AVG)

Razvoj 1. čiste generacije (MAX)

Razvoj 1. čiste generacije (MIN)

Razvoj 2. čiste generacije (AVG)

Razvoj 2. čiste generacije (MAX)

Razvoj 2. čiste generacije (MIN)

Razvoj 3. čiste generacije (AVG)

Razvoj 3. čiste generacije (MAX)

0,9

1,4

Slika 4: Primer rezultata poizvedbe na interaktivni spletni karti 


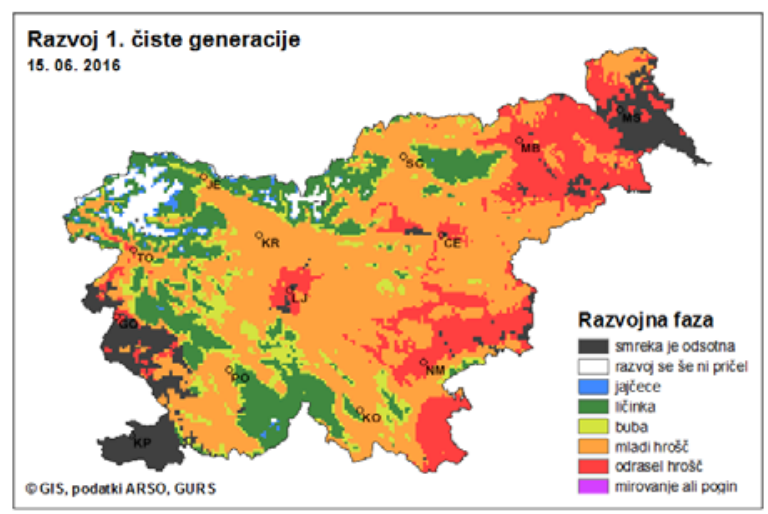

Slika 5: Stanje potencialnega razvoja 1. čiste generacije Ips typographus na dan 15. 6. $2016 \mathrm{v}$ Sloveniji, kakor ga je izračunal model RITY-1 glede na srednjo možnost (AVG)

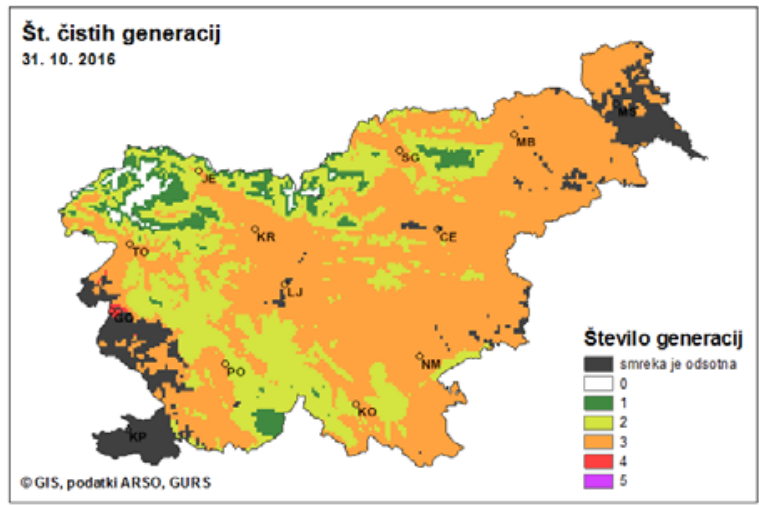

Slika 7: Število potencialnih čistih generacij Ips typographus na dan 31. 10. 2016 v Sloveniji glede na izračun modela RITY-1 (srednja možnost)

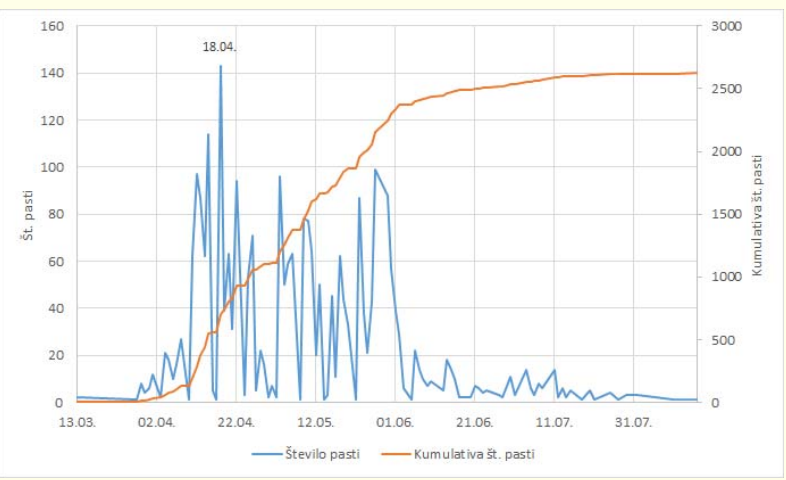

Slika 9: Pričetek spomladanskega rojenja osmerozobega smrekovega lubadarja v kontrolnih pasteh v Sloveniji v letu 2016 (ZGS). V grafu je prikazano število pasti na dan, ko je ulov presegel 100 osebkov na past.

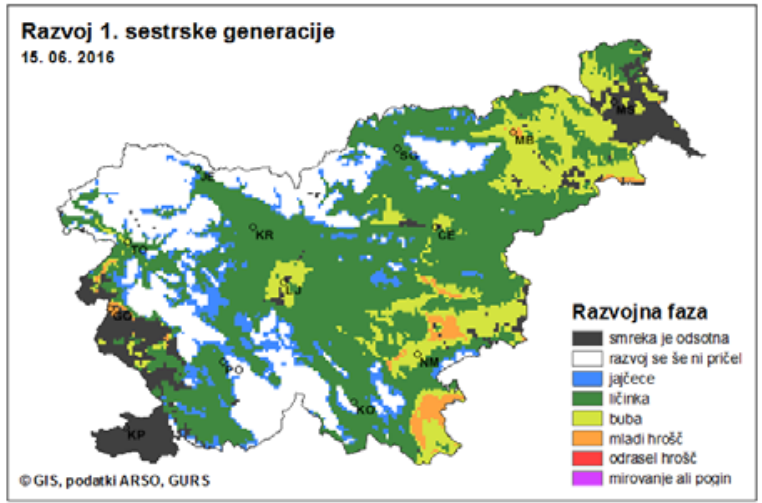

Slika 6: Stanje potencialnega razvoja 1. sestrske generacije Ips typographus na dan 15. 6. $2016 \mathrm{v}$ Sloveniji, kakor ga je predvidel model RITY-1 glede na srednjo možnost (AVG)



Slika 8: Število potencialnih sestrskih generacij Ips typographus na dan 31. 10. 2016 v Sloveniji glede na izračun modela RITY1 (srednja možnost)

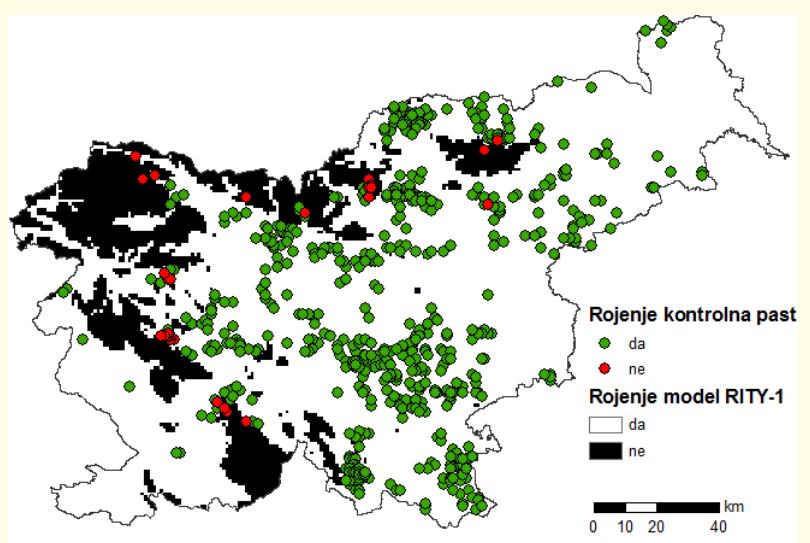

Pripravil: dr. N. Ogris, GIS
Podlage: meja Slovenije (GURS), kontrolne pasti (ZGS).

Slika 10: Primerjava pričetka spomladanskega rojenja osmerozobega smrekovega lubadarja v Sloveniji v letu 2016 med modelom RITY-1-GIS in ulovom $v$ kontrolne pasti 